\title{
Metástase Tiroideia como Manifestação Inicial de um Carcinoma Renal de Células Claras Assintomático
}

\author{
Thyroid Metastasis as the Initial Presentation of an \\ Asymptomatic Clear Cell Renal Carcinoma
}

\author{
Janine CARMELINO $\rrbracket^{1}$, Ana Paula TAVARES ${ }^{1}$, Ana CRESPO ${ }^{1}$, José Mário COUTINHO ${ }^{1}$, António LÁZARO², \\ Vasco RIBEIRO' ${ }^{1}$ Eduardo BARROSO ${ }^{1}$ \\ Acta Med Port 2016 Nov;29(11):755-758 - http://dx.doi.org/10.20344/amp.7277
}

\section{RESUMO}

Introdução: A metastização para a glândula tiroideia de um carcinoma renal de células claras é rara e só diagnosticável após análise imunohistoquímica de uma amostra histológica. O objetivo deste artigo é reportar um caso de metastização tiroideia como primeira manifestação de um carcinoma renal de células claras.

Caso Clínico: Doente do sexo masculino com um nódulo sólido no lobo esquerdo da tiróide, com $5,3 \mathrm{~cm}$, suspeito de malignidade, submetido a tiroidectomia total com linfadenectomia do compartimento central. A análise histológica concluiu serem duas metástases de carcinoma renal de células claras. Após estudo dirigido ao rim, o doente foi submetido a nefrectomia radical quatro meses depois. Discussão: O interesse deste caso reside no facto de a metastização para a tiroide como primeira manifestação de carcinoma renal de células claras ser rara mas, se tratada precocemente, permite uma 'dupla resseção cirúrgica' que pode levar a sobrevidas aos cinco anos de $80 \%$.

Palavras-chave: Carcinoma de Células Renais; Metástase Neoplásica; Neoplasias da Tiróide/secundária.

\section{ABSTRACT}

Introduction: Clear cell renal carcinoma metastases to the thyroid gland are rare and only diagnosable after an immunohistochemistry analysis of the histological sample. The purpose of this article is to report a case of thyroid metastasis as the initial presentation of a clear cell renal carcinoma.

Case Report: Male patient with a solid nodule in the left lobe of the thyroid, $5.3 \mathrm{~cm}$ in diameter, suspicious of malignancy, for which a total thyroidectomy with central compartment lymphadenectomy was performed. Histology revealed two clear cell renal carcinoma metastases. After evaluation of the kidney, the patient underwent radical nephrectomy four months later.

Discussion: What makes this case interesting is that thyroid metastases as the initial presentation of renal cell carcinoma are rare, but if treated early, a 'double surgical resection' is possible, leading to a 5 year survival rate of $80 \%$.

Keywords: Carcinoma, Renal Cell; Neoplasm Metastasis; Thyroid Neoplasms/secondary.

\section{INTRODUÇÃO}

A metastização para a glândula tiroideia é rara e está mais frequentemente associada aos tumores primários do pulmão, mama e rim. ${ }^{1} \mathrm{Em} 10$ anos de análise retrospetiva, Giampaolo Papi et al referem apenas 36 casos de metástases tiroideias ${ }^{1} \mathrm{e}$ a literatura refere que elas representam apenas $2 \%-3 \%$ de todas as neoplasias malignas da tiróide. ${ }^{2}$ Em autópsias foi descrita uma incidência de aproximadamente $1,9 \%-24,2 \%{ }^{3}$

A baixa incidência de metastização para a tiróide deve-se provavelmente ao seu abundante fluxo sanguíneo e à elevada concentração de oxigénio e de iodo no seu parênquima. ${ }^{4}$

As glândulas afetadas por tiroidite, bócio ou neoplasias primárias da tiroide são mais suscetíveis à metastização do que as tiroides saudáveis. ${ }^{2}$

Quando existe uma história prévia de neoplasia renal e quando a análise imunohistoquímica é negativa para tiroglobulina, TTF-1 e calcitonina mas positiva para vimentina e CD10, devemos pensar na hipótese diagnóstica de nódulo metastático. ${ }^{2}$

Cerca de $80 \%$ das metástases tiroideias são detetadas nos primeiros três anos após resseção do tumor primário. Contudo, no caso do carcinoma renal de células claras, tal pode acontecer até 19 anos depois do diagnóstico do tumor primário. $^{3}$

A maioria dos doentes não tem alterações da função tiroideia e vê o nódulo diagnosticado durante exames de imagem de rotina. ${ }^{5}$ Ecograficamente são nódulos difíceis de distinguir dos tumores primários da tiroide. São maioritariamente nódulos hipoecoicos, sem halo periférico ou calcificações, com algumas áreas de degenerescência quística e com bordos irregulares. ${ }^{6,7}$

Tal como os tumores primários da tiroide, cintigraficamente comportam-se na sua maioria como nódulos frios. ${ }^{6}$

A citologia aspirativa com agulha fina tem uma sensibilidade de cerca de $70 \%$ - $80 \%$ no diagnóstico de nódulos metastáticos. A inexistência de história prévia de neoplasia extra-tiroideia dificulta esse diagnóstico., 8

No caso do carcinoma renal de células claras (12\% - 34\% de todos os carcinomas secundários da tiroideia), a sobrevida livre de doença é significativamente melhor no caso de metástases metácronas do que nos casos de metastização

1. Serviço de Cirurgia Geral. Hospital de Curry Cabral. Centro Hospitalar de Lisboa Central. Lisboa. Portugal.

2. Serviço de Anatomia Patológica. Hospital de Curry Cabral. Centro Hospitalar de Lisboa Central. Lisboa. Portugal.

$\square$ Autor correspondente: Janine Carmelino. janine.carmelino@chleiria.min-saude.pt

Recebido: 03 de dezembro de 2015 - Aceite: 01 de agosto de 2016 | Copyright @ Ordem dos Médicos 2016 
síncrona. ${ }^{2,10}$

O tratamento cirúrgico está inequivocamente recomendado nos casos de metastização exclusiva para a glândula tiroideia. Nos casos de metastização múltipla, o prognóstico é menos favorável e a resseção cirúrgica encontra-se indicada sobretudo para paliação de sintomas compressivos. ${ }^{10}$

O objetivo deste artigo é reportar o caso clínico de um doente em que um nódulo tiroideu foi a primeira manifestação clínica de um carcinoma renal de células claras.

\section{CASO CLÍNICO}

Doente do sexo masculino, 48 anos de idade, com antecedentes pessoais de diabetes mellitus tipo 2, obesidade mórbida, hipertensão arterial e esquizofrenia, que recorreu ao seu médico assistente por uma tumefação cervical antero-lateral esquerda com seis meses de evolução e aumento progressivo de dimensões.

$\mathrm{O}$ doente negava antecedentes pessoais ou familiares de patologia da tiroide, sintomas consumptivos, compressivos ou sugestivos de hipo ou hipertiroidismo.

Ao exame objetivo detetou-se uma massa única, elástica, móvel com a deglutição e não aderente aos planos superficial e profundo.

O doente realizou análises laboratoriais que excluíram alterações da função tiroideia ou existência de anticorpos anti-tiroideus. A ecografia cervical revelou uma tiroideia aumentada de volume, com nódulo sólido único no lobo esquerdo, $5,3 \mathrm{~cm}$, globalmente isoecogénico, com degenerescência quística e de limites bem definidos, sem adenomegalias suspeitas.

A citologia aspirativa do nódulo foi classificada como suspeita de malignidade. (Fig. 1).

Após discussão do caso em reunião multidisciplinar, o doente foi submetido em fevereiro de 2015 a lobectomia esquerda da tiroide com exame extemporâneo, cujo resultado foi compatível com carcinoma, a caracterizar após fixação em parafina.

Procedeu-se então à totalização da tiroidectomia com linfadenectomia do compartimento central, atendendo às dimensões e características infiltrativas do nódulo.

O resultado histológico definitivo concluiu existirem dois focos de uma neoplasia epitelial: o maior no lobo esquerdo com $6 \times 4 \times 4 \mathrm{~cm}$ e outro no istmo com $0,8 \mathrm{~cm}$, com marcação positiva para a vimentina e CD10 e negativa para a tiroglobulina, CK7 e CK20.

As características imunohistoquímicas favoreciam uma origem secundária renal da neoplasia. O lobo direito da glândula apresentava hiperplasia nodular, sem outras alterações e os oito gânglios isolados na peça de linfadenectomia não tinham metástases. (Fig.s 2 e 3)

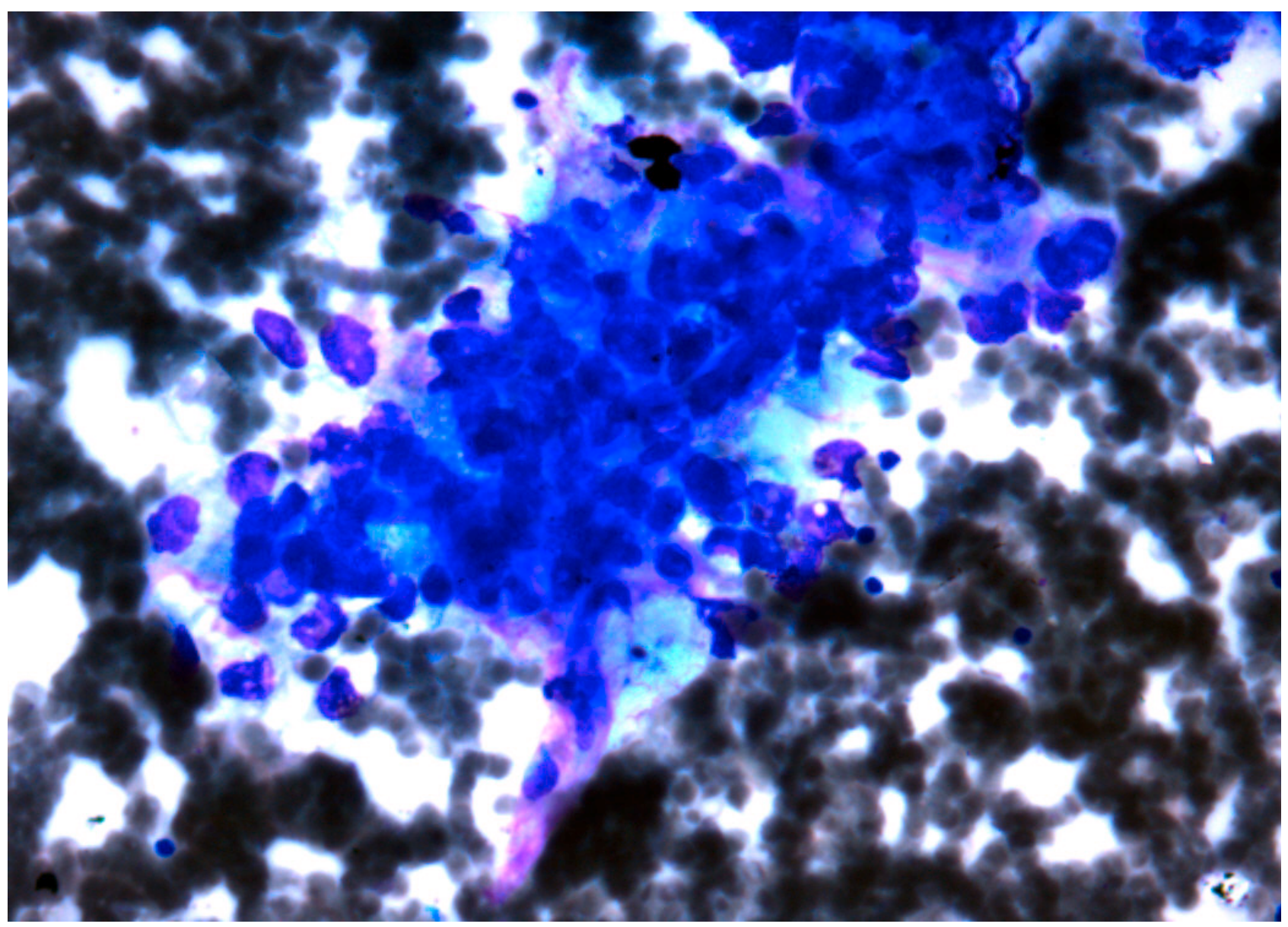

Figura 1 - Citologia aspirativa (MGG ampliação 10X). Agregado de células com atipia nuclear, suspeita de malignidade segundo a classificação de Bethesda. 


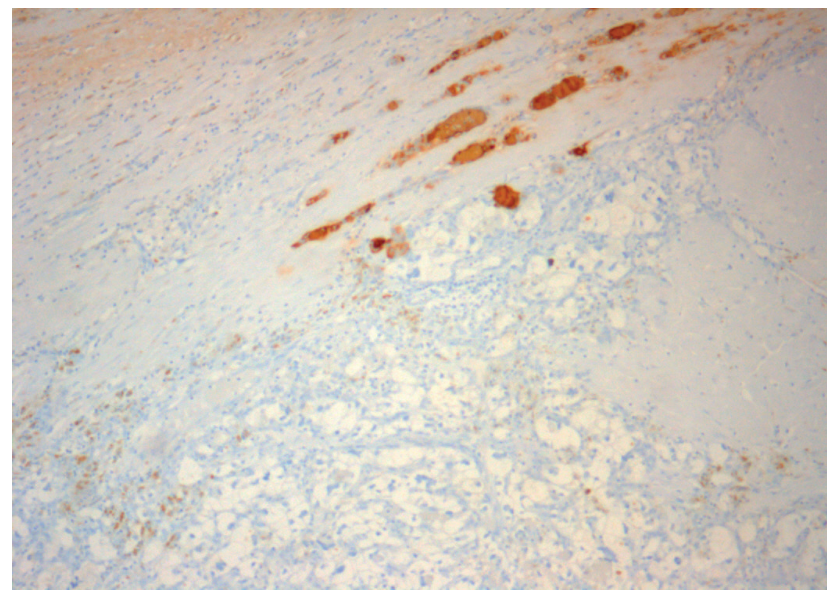

Figura 2 - Histologia definitiva da peça de tiroidectomia total: coloração com tiroglobulina (ampliação 10X). Neoplasia que não fixou a coloração com tiroglobulina, adjacente a região de glândula tiroideia poupada, com células foliculares que reagiram positivamente á coloração com tiroglobulina.

Perante este resultado, o doente realizou uma tomografia computorizada toraco-abdomino-pélvica que comprovou a existência de tumor no rim esquerdo, com $10 \mathrm{~cm}$ de maior diâmetro e extensão para a gordura péri-renal. Não se detetaram sinais de invasão vascular, adenopatias suspeitas ou metastização à distância. (Fig. 4)

$O$ doente foi submetido a nefrectomia radical esquerda por lombotomia, em junho de 2015, sem intercorrências. Não se detetaram intra-operatoriamente adenopatias suspeitas, pelo que não se procedeu a disseção ganglionar.

O resultado histológico da peça de nefrectomia foi de carcinoma de células renais, variante células claras clássica (Grawitz) com 9,5 cm de maior diâmetro, com invasão focal da gordura mas sem invasão vascular ou da árvore pielocalicial (pT3N x M1) - Fig.5.

À data da submissão deste artigo, seis meses após a última intervenção cirúrgica, o doente encontra-se clinicamente bem, sem sinais de recidiva local ou à distância.

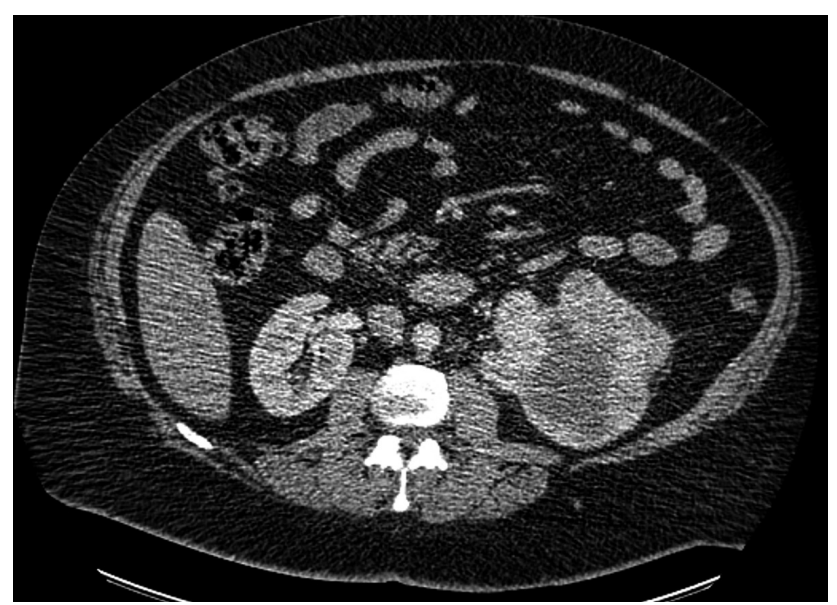

Figura 4 - Tomografia computorizada abdomino-pélvica com contraste endovenoso e oral onde se observa tumor no rim esquerdo com $10 \mathrm{~cm}$ de diâmetro, captação heterogénea do contraste, ausência de invasão vascular ou da árvore pielocalicial, com extensão para a gordura péri-renal.

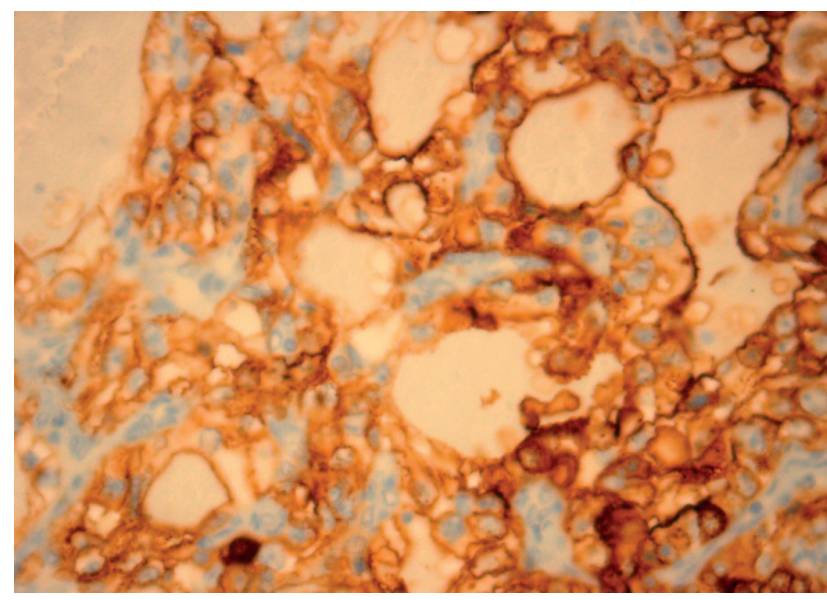

Figura 3 - Histologia definitiva da peça de tiroidectomia total: coloração com vimentina (ampliação 40X). Agregado de células atípicas que reagiram positivamente á marcação com vimentina.

\section{DISCUSSÃO}

Este caso reflete uma situação rara de metastização para a glândula tiroideia de um carcinoma renal de células claras assintomático.

Apesar de a citologia aspirativa ter permitido concluir tratar-se de um nódulo suspeito de malignidade, apenas a análise imunohistoquímica da peça operatória permitiu um diagnóstico definitivo, e consequentemente o posterior diagnóstico do tumor renal.

A metastização para a glândula tiroideia como manifestação inicial de um carcinoma de células claras renais é rara. Pelo que apurámos há apenas um caso descrito na literatura de uma metástase tiroideia, diagnosticada após tiroidectomia total efectuada por suspeita de tumor primário da tiróide. ${ }^{11}$

Mesmo sabendo que as metástases tiroideias de carcinoma renal de células claras representam apenas 0,07\% de todos os nódulos tiroideus, nestes casos o seu diagnóstico e tratamento pode determinar o prognóstico da lesão

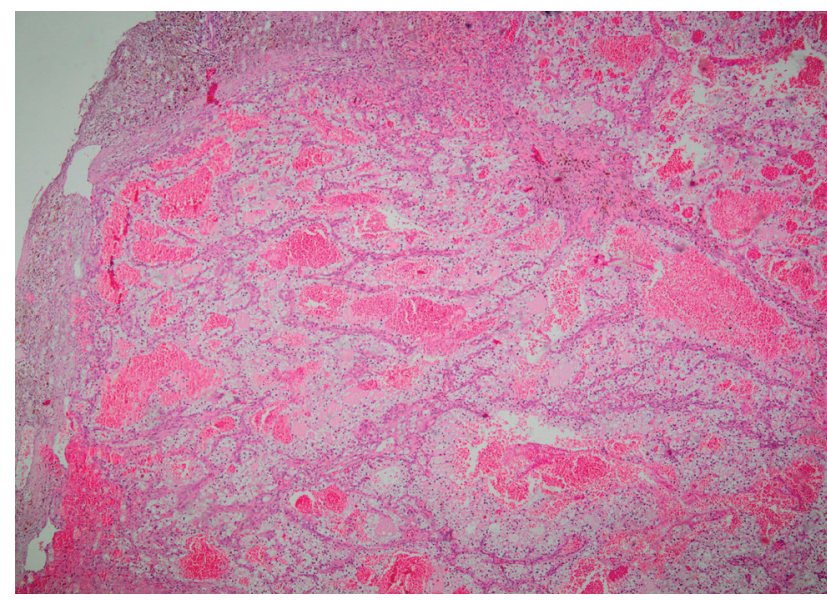

Figura 5 - Histologia definitiva da peça de nefrectomia radical: coloração com hematoxilina-eosina (ampliação 10X). Neoplasia de padrão sólido com células claras. 
primitiva ${ }^{12}$

A sobrevivência média cinco anos após esta 'dupla resseção' pode chegar a $80 \%$, contra os $5 \%$ descritos nos casos em que já ocorreu disseminação para outros órgãos. ${ }^{11}$

Neste caso, só o seguimento a longo prazo permitirá avaliar o impacto da metastização síncrona exclusiva para a glândula tiroideia, na sobrevida livre de doença.

\section{PROTECÇÃO DE PESSOAS E ANIMAIS}

Os autores declaram que os procedimentos seguidos estavam de acordo com os regulamentos estabelecidos pelos responsáveis da Comissão de Investigação Clínica e Ética e de acordo com a Declaração de Helsínquia da Associação Médica Mundial.

\section{REFERÊNCIAS}

1. Papi G, Fadda G, Corsello SM, Corrado S, Rossi ED, Radighieri E, et al. Metastases to the thyroid gland: prevalence, clinic pathological aspects and prognosis: a 10-year experience. Clin Endocrinol. 2007;66:565-71.

2. Medas F, Calò PG, Lai ML, Tuveri M, Pisano G, Nicolosi A. Renal cell carcinoma metastasis to thyroid tumor: a case report and review of the literature. J Med Case Rep. 2013;7:265.

3. Chen $\mathrm{H}$, Nicol TL, Udelsman R. Clinically significant, isolated metastatic disease to the thyroid gland. World J Surg. 1999;23:177-80;

4. Kihara M, Yokomise $H$, Yamauchi A. Metastasis of renal cell carcinoma to the thyroid gland 19 years after nephrectomy: a case report. Auris Nasus Larynx. 2004;31:95-100.

5. Foppiani L, Massollo M, Del Monte P, Bandelloni R, Arlandini A, Piccardo A. Late-onset metastasis of renal cell carcinoma into a hot thyroid nodule: an uncommon finding not to be overlooked. Case Rep Endocrinol. 2015;2015:268714.

6. Mohammadi A, Toomatari SB, Ghasemi-Rad M. Metastasis from renal cell carcinoma to thyroid presenting as rapidly growing neck mass. Int $J$ Surg Case Rep. 2014;5:1110-2.

\section{CONFIDENCIALIDADE DOS DADOS}

Os autores declaram ter seguido os protocolos do seu centro de trabalho acerca da publicação de dados.

\section{CONFLITOS DE INTERESSE}

Os autores declaram não terem qualquer conflito de interesse relativamente ao presente artigo.

\section{FONTES DE FINANCIAMENTO}

Os autores declaram não ter recebido subsídios ou bolsas para a elaboração do artigo.

7. Yook JH, Kim EY, Kwak JY, Moon HJ, Kim GR. Sonographic features and ultrasonography-guided fine-needle aspiration of metastases do the thyroid gland. Ultrasonography. 2014;33:40-8.

8. Lacka K, Breborowicz D, Uliasz A, Teresiak M. Thyroid metastases from a breast cancer diagnosed by fine-needle aspiration biopsy. Case report and overview of the literature. Exp Oncol. 2012;34:129-33.

9. Chung AY, Tran TB, Brumund KT, Weisman RA, Bouvet M. Metastases to the thyroid: a review of the literature from the last decade. Thyroid. 2012; 22:258-68.

10. Rizzo M, Rossi RT, Bonaffini O, Scisca C, Sindoni A, Altavilla G, et al. Thyroid metastasis of clear cell renal carcinoma: Report of a case. Diagn Cytopathol. 2009;37:759-62.

11. Ramírez-Plaza CP, Domínguez-López ME, Blanco-Reina F. Thyroid metastasis as initial presentation of clear cell renal carcinoma. Int J Surg Case Rep. 2015;10:101-3.

12. Benoit L, Favoulet P, Arnould L, Margarot A, Franceschini C, Collin F, et al. Metastatic renal cell carcinoma to the thyroid gland: report of seven cases and review of the literature. Ann Chir. 2004;129:218-23.

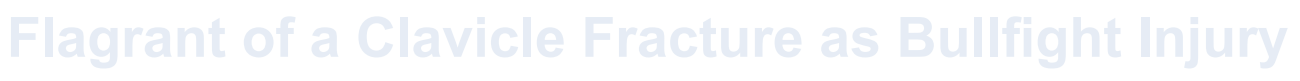

